\title{
SOBRE A DIVERSIDADE DE FORMATOS E ATORES SOCIAIS NO CAMPO DA ECONOMIA SOLIDÁRIA
}

\author{
Marilia Verissimo Veronese* \\ Luiz Inácio Gaiger* * \\ Adriane Vieira Ferrarini***
}

\begin{abstract}
O artigo apresenta um entendimento dos empreendimentos econômicos solidários a partir da realidade multiforme da economia solidária no Brasil. Trata-se de um conjunto variado de iniciativas ainda em busca de identidade institucional e de um arcabouço jurídico condizente, que não cabem no cooperativismo tradicional nem no chamado terceiro setor. Valendo-se de um conjunto de estudos já conduzidos, tanto em termos de conceituação e formulação tipológica como de desenho etnográfico, o texto reflete sobre a configuração plural dos empreendimentos solidários, analisando diferentes atores sociais em foco, urbanos, rurais e tradicionais, procurando demonstrar a diversidade cultural e simbólica ali existente, bem como suas múltiplas origens e desafios atuais, a exemplo da busca de um marco legal específico para o campo.

Palavras-chave: Sociologia. Empreendimentos solidários. Diversidade Cultural. Associativismo. Práticas Tradicionais e Autóctones.
\end{abstract}

\section{INTRODUÇÃO}

Na realidade da economia solidária no Brasil, temos um conjunto amplo e variado de iniciativas ainda em busca de identidade institucional e de um arcabouço jurídico condizente, que não cabem no cooperativismo tradicional nem no chamado terceiro setor. Como partícipes de uma nova onda de solidarismo social e econômico, elas eventualmente se contrapõem às formas cooperativas tradicionais, já institucionalizadas na forma do cooperativismo. Com esse enfoque crítico, tais iniciativas, denominadas empreendimentos econômicos solidários (EES), têm passado por um processo de reconhecimento mútuo e de unificação, alinhando-se gradativamente ao campo denominado como economia solidária.

\footnotetext{
* Universidade do Vale do Rio dos Sinos (UNISINOS). Programa de Pós Graduação em Ciências Sociais.

Av. Unisinos, 950. Cristo Rei. Cep: 93022-750. São Leopoldo - Rio Grande do Sul - Brasil. mariliav@unisinos.br

** Universidade do Vale do Rio dos Sinos (UNISINOS). Programa de Pós Graduação em Ciências Sociais. Av. Unisinos, 950. Cristo Rei. Cep: 93022-750. São Leopoldo - Rio Grande do Sul - Brasil. gaiger@unisinos.br

${ }^{* * *}$ Universidade do Vale do Rio dos Sinos (UNISINOS). Programa de Pós Graduação em Ciências Sociais.

Av. Unisinos, 950. Cristo Rei. Cep: 93022-750. São Leopoldo - Rio Grande do Sul - Brasil. adrianeferrarini@gmail.com
}

Esse termo ganhou expressão e oficialidade no Brasil a partir dos anos 1990, à medida que despontaram no país iniciativas econômicas notabilizadas e reconhecidas por sua natureza associativa e suas práticas de cooperação e autogestão. Ao expandir-se, a economia solidária veio a abarcar diversas categorias sociais e variadas modalidades de organização, como unidades informais de geração de renda, associações de produtores e consumidores, sistemas locais de troca, comunidades produtivas autóctones e cooperativas, dedicadas à produção de bens, à prestação de serviços, à comercialização e ao crédito. Geralmente, o foco principal desses grupos é a geração de bem-estar social e sobrevivência digna para seus associados. Este texto procura demonstrar como a diversidade cultural na constituição dos empreendimentos é bem maior do que costuma ser considerado, predominantemente em termos de cooperativismo urbano ou rural. As formas de ser e de estar no mundo são sensivelmente diversas em um grupo quilombola, numa associação de pescadores artesanais, ou numa cooperativa urbana integrada à economia das grandes cidades. Tal miríade de práticas sociais abre um 
campo de pesquisa para que se (re) conheçam a importância e as qualidades dessas diferenças, no âmbito das distintas formas de associação. Embora a identidade cultural não forneça uma essência única a um grupo, pois, para Hall (1996), as culturas são contraditórias em seu próprio interior, estando sempre em mutação, reafirmamos a importância de que, através de sentidos relativamente estáveis, as comunidades culturais possam se reconhecer, se representar e serem, assim, reconhecidas pela sociedade de entorno. Na economia solidária, a importância da cultura que marca cada experiência de associação com referências próprias é significativa, para que elas possam desenvolver seus produtos, serviços e práticas dotados de singularidade e criatividade.

Segundo estudos de referência (Cattani et al., 2009; Gaiger, 2004; Pinto, 2006; Singer; Souza, 2000), a primazia da solidariedade em tais empreendimentos manifesta-se no envolvimento de seus membros com a gestão cotidiana, na socialização dos recursos produtivos e na adoção de princípios de equidade. Quando estendida a seu entorno, a solidariedade pode estimular práticas ampliadas de reciprocidade, nas quais as vivências concretas de gestão do bem comum conferem um novo valor às noções de justiça e de interesse público. O agir coletivo da economia solidária institui, então, as figuras que não se enquadram no cooperativismo convencional, incluindo os povos tradicionais, como quilombolas, pescadores artesanais, comunidades indígenas e ribeirinhas, de fundos de pasto, quebradeiras de coco e outros atores sociais diversos. Consideramos que essa grande pluralidade precisa de maior detalhamento analítico por parte das pesquisas no campo da economia solidária.

A próxima seção resume, em grandes linhas, alguns dos antecedentes da economia solidária no Brasil, com o objetivo de esclarecer os pontos de continuidade e as linhas divisórias entre experiências mais antigas e mais recentes. Destaque será dado, ainda, nas seções seguintes, aos antecedentes históricos das manifestações empíricas do campo (seção 1), aos formatos mais conhecidos - cooperativas e associações -, que não esgotam a diversidade encontrada (seção 2), à vertente da economia popular (seção 3) e ao lugar da tradição nas origens e atualidade dos EES (seção 4), procurando dar conta das características peculiares da economia solidária quanto à diversidade de culturas nela presente, e nas razões de sua incompatibilidade com as alternativas jurídicas atualmente disponíveis para seus empreendimentos. A seção 5 consiste num comentário final, à guisa de conclusão, com indicações de agendas de pesquisa para temática da economia solidária.

\section{CARACTERIZAÇÃO DO CAMPO E ALGUNS ANTECEDENTES HISTÓ- RICOS}

Nos dias atuais, a economia solidária evoca um amplo conjunto de sujeitos, de organizações econômicas, de entidades representativas e de organismos da sociedade civil e do Estado. Ela designa, ao mesmo tempo, um setor econômico e um movimento social. Por ser um fenômeno ainda recente e não encontrar soluções jurídicas adequadas no Direito vigente, a economia solidária encontra-se despro- 
vida de um marco legal apropriado no Brasil. Suas organizações, designadas genericamente de empreendimentos, não podem ser apreendidas corretamente apenas a partir do formato jurídico oficial que adotam, ou deixam de adotar - no caso dos grupos informais e sem compromissos de mais longo termo -, uma vez que ele representa, em geral, uma solução paliativa para que possam funcionar e tornarem-se viáveis.

Conforme o segundo Mapeamento Nacional de Economia Solidária concluído em 2013, cerca de 30\% dos empreendimentos econômicos solidários é constituído de grupos informais, isto é, que não se regulam por nenhum dispositivo legal, mas por normas próprias, internas. Em tais circunstâncias, inexistem critérios consagrados ou de ampla aceitação para fins de distinção e classificação dos empreendimentos, sendo inapropriado suprir essa lacuna recorrendo a argumentos formais. O conjunto das pesquisas já conduzidas nos autoriza a refletir sobre eventuais estereótipos construídos sobre esse campo, a partir da discussão sobre sua diversidade.

Conforme bibliografia disponível (Gaiger, 2004; Singer; Souza , 2002), os princípios que caracterizam a economia solidária são conhecidos desde a instauração do capitalismo industrial, no séc. XIX, quando impulsionaram as vertentes associativas, mutualistas e cooperativas sobre as quais se edificou a experiência da economia social, em vários países do Norte e alguns países do Sul. O solidarismo foi uma resposta de trabalhadores submetidos à proletarização diante da turbulência social causada pela revolução industrial.

Em termos de origens da economia solidária contemporânea, porém, convém mencionar que existem distintas vertentes em diferentes contextos históricos, espaçotemporais. Já nas primeiras décadas do século XX, a economia social europeia, comumente citada como uma das origens da economia solidária atual, se opôs às tendências de redução da economia capitalista ao princípio do mercado e à racionalidade da acumulação privada. Com isso, desempenhou um papel considerável na construção dos regimes de bem-estar social naquele continente. A partir dos anos 1970, com a crise de regulação keynesiana e o desequilíbrio social resultante, uma série de novas experimentações sociais teve lugar, revigorando as práticas associativas e de solidariedade econômica. A economia social, ao norte, retomou seu elã crítico e participativo, ao mesmo tempo em que experiências análogas surgiram ou se revitalizaram em países do Sul. Distintas realidades empíricas manifestaram-se, assim, em diferentes contextos.

No contexto latino-americano, por exemplo, associações, grupos informais, cooperativas, empresas de autogestão, iniciativas locais no campo dos serviços sociais e de assistência a pessoas necessitadas, empresas sociais e finanças solidárias, além de mecanismos correlatos de fomento e de organizações representativas, expandiram-se entre categorias sociais colocadas à margem dos sistemas convencionais de ocupação e renda, ou frustradas em suas aspirações individuais e coletivas.

O que importa ressaltar é a diversidade de aspirações que estão na base da constituição de muitas experiências, do sul ao norte, a partir do momento em que começam a ser vistas como constitutivas de uma pluralidade econômica, considerando a referida crise e seus efeitos globais. Não é somente a pobreza e a precariedade que fazem surgir um empreendimento econômico solidário (EES), mas também são necessárias aspirações a uma vida melhor e a uma racionalidade projetiva, ${ }^{1}$ por vezes pautada em lutas políticas históricas, por vezes, parte de uma cultura ancestral, tradicional.

Embora tenha ganhado notoriedade a partir de sua expansão recente, nos anos 1990, a economia solidária dá continuidade e novo alento a uma história extensa, na qual se con-

${ }^{1}$ Uma forma de visão de mundo que projeta um futuro a partir de valores específicos, como respeito à natureza, liberdade, solidariedade, justiça, igualdade etc.; ou seja, transcende objetivos meramente de geração de renda e abrange visões de futuro projetadas axiologicamente. 
tam inúmeras experiências de solidarismo popular. No Brasil, como na América Latina em geral, a economia solidária possui antecedentes longínquos, a começar pelas formas autóctones pré-colombianas e pelos sistemas coletivos adotados pelos escravos libertos (no Brasil, os quilombolas). Dedicaremos ao tema uma seção do texto, por considerarmos importante ressaltar também essa origem das práticas de solidarismo. Segundo dados atuais do mapeamento nacional da economia solidária, cerca de $11 \%$ das experiências mapeadas é formada pelos chamados povos tradicionais (Gaiger, 2014). Na paisagem social cambiante do continente latino-americano, passa-se rapidamente de iniciativas determinadas pela condição precária de trabalhadores assalariados, ao mesmo tempo subalterna e integrada às engrenagens do subdesenvolvimento periférico, às zonas em que predominam coletividades - em especial, os povos originários - que preferiram proteger os seus sistemas de vida e afastar-se do mercado de trabalho capitalista, evitando, assim, sua dissolução, a perda de referências culturais, ou mesmo, seu extermínio.

Além desses antecedentes mais distantes, também é preciso notar que o surto recente de empreendimentos e de mobilizações sociais, que tornaram a economia solidária um fato público, foi precedido de iniciativas congêneres à altura se enraíza o solidarismo econômico, atentando, de outra feita, para os processos sociais das úl- timas décadas, que culminaram paulatinamente na formação de um novo campo de práticas de solidariedade, portador de inovação social e de novas expectativas. Como se refere Rui Namorado (2004), uma constelação de esperanças constituída por diferentes sujeitos.

\section{OS FORMATOS MAIS CONHECI- DOS: associações e cooperativas}

Nesta seção, trataremos daqueles formatos que são mais reconhecidos no âmbito do trabalho associativo, mas que certamente não esgotam a diversidade de formatos e racionalidades encontradas. No Brasil, sempre subsistiram práticas econômicas fundamentadas no trabalho e escoradas em laços de reciprocidade, nas quais a produção material atende a necessidades coletivas e guarda um sentido primordialmente social. Desde fins do século XIX, em paralelo ao domínio do capitalismo, estratégias associativas e cooperativas buscaram assegurar condições de vida a importantes contingentes e, ademais, mantiveram em vigor princípios de produção de bens, de organização do trabalho e de circulação da riqueza distintos da racionalidade estrita do capital. Trata-se de uma resistência histórica, orientada por valores cuja defesa se fez a duras penas, e não logrou impedir desvios de rota e importantes concessões em seus princípios originais.

O Brasil não chegou a conhecer um associativismo similar àquele do séc. XIX europeu, gerador da moderna economia social naquele continente, embora a vida comunitária tenha sido marcante em muitas regiões e propostas autogestionárias de organização tenham sido frequentes no movimento operário, até o advento dos regimes populistas, nos anos 1930, quando o Estado chamou a si os rumos do desenvolvimento econômico e social. Com exceções momentâneas, as tentativas de os trabalhadores construírem alternativas pela via associativa não lograram converter-se em um movimento realmente classista, de contrapo- 
sição à lógica do capital fundiário, comercial e industrial. Permaneceram dependentes da estrutura econômica regional, da cultura dos trabalhadores em questão e dos espaços - limitados - encontrados nos jogos de poder.

Comparando-se a experiência brasileira com aquela da economia social na Europa, com seus três ramos - mutualista, associativo e cooperativo - deve-se adiantar que, em relação à vertente mutualista, iniciativas de ajuda mútua (caixas laborais, pecúlios, etc.), desenvolvidas principalmente por agricultores familiares e trabalhadores urbanos, ficaram vinculadas, no Brasil, ao universo associativo e ao setor cooperativo, sem constituir um setor mutualista propriamente dito. Em certos casos, tais iniciativas persistiram como modalidades autóctones de organização e valorização da vida comunitária. Mas, em geral, os serviços por elas prestados, sobretudo em saúde e educação, foram incorporados em novas dinâmicas institucionais, principalmente a filantropia privada (religiosa, benemerente) e a estatal, degenerando, com frequência, para padrões assistencialistas e funcionando como via auxiliar de preservação hegemônica das elites políticas locais.

Por sua vez, o associativismo desempenhou um papel histórico relevante, especialmente para pequenos produtores familiares, desde o momento em que ocuparam o espaço agrário brasileiro, no correr do século XIX. Contudo, até os dias de hoje, o marco legal das associações é extremamente amplo, pois abrange toda agremiação de pessoas que se unem para desenvolver atividades comuns, desde que se distingam de instituições mais específicas (igrejas, fundações e partidos políticos) e não tenham finalidade econômica. Com isso, o associativismo manteve-se sem personalidade própria e sem mecanismos de representação, tendo sido, ademais, largamente cooptado ou estimulado para funcionar como correia auxiliar da dominação oligárquica. ${ }^{2}$

\footnotetext{
${ }^{2}$ No interior do país, foi prática comum criar ou favorecer associações em troca da fidelidade de seus membros aos senhores - caudilhos e coronéis - dos quais emanava o
} poder político e provinham as elites dirigentes.
As associações, conforme disciplina o Código Civil (CC) brasileiro de 2002, são pessoas jurídicas de direito privado (Art. 44, I do CC), constituídas por associados (pessoas naturais ou jurídicas) que, unidos, se organizam para fins não econômicos (caput do Art. 53 do CC). O que fazem os empreendimentos da economia solidária, porém, é usar um dispositivo legal que se destina a fins não econômicos para poder ter um resguardo jurídico mínimo, uma configuração que lhes permita atuar na legalidade, com CNPJ. A lei das cooperativas é de 1971, já as instituindo como empresas econômicas, ao passo que as associações não eram assim consideradas, o que não muda no novo código de 2002. Cabe ressaltar ainda que, conforme disciplina o Art. 981 do CC, "celebram contrato de sociedade as pessoas que reciprocamente se obrigam a contribuir, com bens ou serviços, para o exercício de atividade econômica e a partilha, entre si, dos resultados" (Brasil, 2002; grifos nossos). Ou seja, no que concerne à parte do conceito grifada, resta claro que as cooperativas situam-se entre aquilo que se pode juridicamente determinar como associação, pela sua forma organizativa, e sociedade, pelo seu fim econômico. Possuem, contudo, forma específica, delimitada pela chamada Lei Geral das Cooperativas (Lei no 5764/1971).

Cumpre ressaltar que outro diferencial que se pode estabelecer em relação às associações e cooperativas é que, quanto ao registro, as primeiras necessitam de um processo mais simples para atingirem sua existência legal (Art. 45 do CC c/c Art. 119 da Lei de Registros Públicos), enquanto as segundas necessitam, além das averbações a que se refere a Lei de Registros Públicos (Lei ${ }^{\circ}$ 6015/1973), de autorização de funcionamento e de registro na Junta Comercial competente, conforme Artigos 17 a 20 da Lei Geral das Cooperativas. Desse modo, fica demonstrado que o ato de constituir uma cooperativa é mais demorado e dispendioso do que aquele de formar uma associação, motivo suficiente para se imaginar o porquê da eventual escolha, por parte dos grupos, de se torna- 
rem associação e não cooperativa.

Por trás das associações, há muitas histórias e formas, dentre elas o associativismo genuinamente popular. Desde os anos 1970, no contexto dos fluxos demográficos que resultaram nas atuais aglomerações urbanas, a associação tem sido um instrumento popular de organização e de luta pelo direito à moradia e a melhores condições de vida. É notório o papel desempenhado pelas associações comunitárias, como esteios de mobilizações sociais mais amplas, como as lutas democráticas e os embates eleitorais que provocaram a renovação dos partidos políticos e a guinada de governos à esquerda. Ao mesmo tempo, as associações funcionaram como núcleo de iniciativas locais, dando-lhes impulsão e resguardo institucional. Projetos comunitários de geração de renda e desenvolvimento econômico buscaram também o respaldo jurídico das associações. O resultado disso é um híbrido: atividades comunitárias de natureza social fundem-se a empreendimentos com finalidade econômica, em si mesma desguarnecida de amparo jurídico. Essa solução evita a informalidade plena, mas posterga a formalização econômica do empreendimento, que, assim, fica privado das prerrogativas e vantagens do exercício legal das suas atividades. Cabe lembrar, também, que alguns EES decidem permanecer na informalidade para evitar os custos da

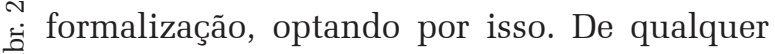
modo, é questão frequentemente discutida nas assembleias e reuniões que os associados realizam, uma vez que formalizar-se nem sempre é opção viável ou desejável. Da mesma forma, or no meio rural, de longa data, as associações de $\stackrel{\wedge}{\curvearrowright}$ pequenos agricultores dão suporte a disposiले tivos coletivos de produção, comercialização

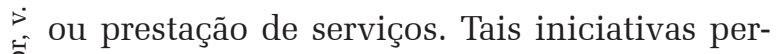
manecem, via-de-regra, restritas em seus fins e espaços de atuação, mas têm preservado a cultura associativa no meio rural, lastreando as iniciativas que hoje prevalecem entre os empreendimentos solidários.

Em nossos dias, a associação é o formato jurídico predominante na Economia solidária. ${ }^{3}$

Sua adoção confere um status institucional aos empreendimentos para que funcionem na semiformalidade, recebam apoios e subvenções. Mas, como demonstraram alguns estudos (Pinto, 2006), o ato associativo, nesses casos, vai além do espírito pragmático. Ele traduz uma trajetória coletiva na qual se forjaram identidades e práticas solidárias, agora revalorizadas. Como resultado disso, no espaço rural e urbano, os empreendimentos solidários, em geral, se inserem em estruturas coletivas mais amplas, o que lhes permite vencer o estado de abandono e isolamento da produção familiar e das micro e pequenas empresas. São iniciativas desse tipo que vicejaram nos anos 1980, antes do boom da economia solidária.

A lei complementar $n^{0} 128$, em 2008, cria ainda a figura do Microempreendedor Individual (MEI), com o intuito de formalizar atividades empresariais de pequeno porte. Esse pode eventualmente ser um modo de formalização que cria algumas contradições com a ideia de associativismo, embora não disponhamos de dados, no momento da escrita deste texto, para afirmar como e em que medida tal situação se manifesta. Mas o fato é que tais situações específicas precisam ser mais investigadas, indicando futuras agendas de pesquisa.

Dos três braços da economia social (no seu sentido europeu), apenas o cooperativismo alcançou um patamar institucional próprio no Brasil, embora sempre permeado por concepções e interesses diversos e sendo objeto permanente de disputas. A introdução das cooperativas no país ocorreu originalmente por obra de imigrantes europeus, no final do século XIX, como forma de vencer as situações de flagrante desamparo em que viviam. Nesses primórdios, surgiram cooperativas de consumo, bem como de crédito e agropecuárias, especialmente no Sul do país, de colonização europeia. As cooperativas de consumo expandiram-se nos anos

${ }^{3}$ Conforme o segundo mapeamento nacional da Economia solidária no Brasil, 60\% dos EES são associações, 30\% são organizações informais e 8,8\%, cooperativas (dados de 2013). 
1950 e 1960. Posteriormente, o cooperativismo urbano apresentou sinais de estagnação, atribuível ao desestímulo oficial, do que resultou uma série de barreiras à sua expansão e sobrevivência. À medida que o desenvolvimento econômico favoreceu a expansão das grandes empresas capitalistas, estimulou-as a substituírem os serviços antes prestados pelas cooperativas (Schneider; Lauschner, 1979).

Hoje, grandes cooperativas funcionam como empresas de capital, voltadas para a lucratividade no mercado, empenhadas na profissionalização e na racionalização administrativa. Há também as pequenas cooperativas em periferias urbanas, voltadas para a inserção socioeconômica e o atendimento a necessidades básicas de populações pobres, que tendem a apresentar índole mais igualitarista, valorizam o fato de se governarem coletivamente e se identificam com a economia solidária (Anjos, 2012; Nunes, 2001). Ao lado delas, existe o fenômeno das falsas cooperativas, que se valem do marco legal cooperativo para intermediarem mão de obra a baixo custo, mantendo intacta a hierarquia da empresa e a divisão entre capital e trabalho. O cooperativismo brasileiro, por conseguinte, apresenta-se heterogêneo quanto à natureza e à escala de suas atividades, à complexidade das organizações cooperativas e, fundamentalmente, a seus princípios ideológicos.

Nesse contexto contraditório, a economia solidária ensejou uma nova geração de cooperativas, motivadas pela convicção de que esse formato, mesmo imperfeito, constitui o modelo mais acabado de autogestão e de solidariedade econômica, sendo a base de um sistema adequado para atender aos interesses dos trabalhadores. Com essa finalidade, as cooperativas solidárias se têm alinhado em favor de um novo modelo, questionador do perfil político e dos impasses do cooperativismo no país, relacionados à incoerência entre seus princípios doutrinários e seu desenvolvimento histórico. Tal modelo viria a suplantar o cooperativismo tradicional e a recuperar as cooperativas desvirtuadas pela centralização do poder ou criadas de modo fraudulento, como um estratagema empresarial de desoneração de custos sociais. O êxito dessas estratégias e a viabilidade das cooperativas solidárias dependem, no entanto, de sua capacidade de gerar ambientes socioeconômicos que não as ameacem, mas as fortaleçam, convertendo-as em um nódulo diferenciado e expansível no interior do sistema econômico atual, mesmo que, eventualmente, confrontando-o em termos políticos.

\section{O CONTEXTO DA ECONOMIA PO- PULAR}

O advento da economia solidária pode situar-se na contracorrente desse legado histórico, cuja descontinuidade e limitada institucionalização explica por que o conceito de economia social jamais tenha sido empregado no Brasil, exceção feita a estreitos círculos acadêmicos. Não obstante, tais antecedentes subjazem às práticas atuais de economia solidária, como também nela subsistem formas atávicas de solidariedade, mal conhecidas e pouco reconhecidas. A esse lastro social somaram-se, recentemente, novas modalidades de ação coletiva, de sorte que, para completar essa retrospectiva histórica, é preciso examinar as mudanças transcorridas na sociedade brasileira durante as últimas décadas. Nesse período, despontou uma das principais vertentes da economia solidária, tanto no Brasil quanto na América Latina: a economia popular, e seu corolário, a informalidade.

Desde os anos 1970, uma população de trabalhadores em franco crescimento demográfico, pressionada pela contração das oportunidades econômicas no meio rural e pelos atrativos do crescimento industrial e urbano, evadiu-se em grandes proporções para as cidades, deparando-se com a incapacidade de absorção pelo mercado formal de trabalho e com a falta de instrumentos para inserir-se estavelmente na economia formal. Compelido a sobreviver de trabalhos por conta própria e de 
ocupações temporárias informais, esse contingente modificou a paisagem urbana, expandindo os bairros periféricos pobres e convertendo a economia informal em um fenômeno de grande magnitude. A informalidade deixou de ser negligenciada como um resíduo marginal e temporário do capitalismo, ou como um elemento funcional incorporado ao exército industrial de reserva, passando a ser entendida como um traço estrutural do desenvolvimento capitalista, irreversível no quadro solidamente instituído por modelos socialmente excludentes.

Segundo o DIEESE (2016), o SIES revelou, no segundo mapeamento nacional, que o grau de informalidade na economia solidária era de 50,4\%, considerando os 19.708 EES mapeados. Interessante destacar que essa informalidade não é atributo somente dos que se declaram como tal, mas também de alguns EES que se declaravam como associações, cooperativas ou sociedades mercantis, porém não informavam CNPJ, conforme o estudo realizado com base no SIES e RAIS.

Com o passar dos anos, o alastramento e a perseverança da informalidade levaram a perceber que ela se inseria em estratégias mais amplas de sobrevivência, mediante as quais os setores populares mostravam-se capazes de se organizar e instituir frentes de mobilização. De fato, novos movimentos sociais surgiram nas Fै periferias, lutando por moradia, serviços urt. banos, renda e direito ao trabalho. Iniciativas comunitárias se multiplicaram e despertaram ह $\mathrm{o}$ interesse paulatino de organizações civis, ळ da Libertação e instituições de microcrédito, $\dot{2}$ artífices dos bancos da mulher, predecessores $\stackrel{\wedge}{A}$ das iniciativas atuais de finanças solidárias. §ं Pipocaram comunidades de base, associações $\dot{1}$ de moradores e uniões de produtores familiares, das quais surgiriam, nos anos 1980, as primeiras experiências coletivas de geração de renda, germes da Economia Solidária contemporânea no Brasil e em muitos países da América Latina.

Nesse novo contexto, a informalida- de foi reinterpretada como parte também da economia popular, isto é, de modalidades de sobrevivência propensas à defesa dos vínculos comunitários e ao associativismo. Essas formas de sobrevivência passaram a ser analisadas a partir de sua racionalidade intrínseca, orientada para a preservação de um fundo de trabalho (Coraggio, 1999), por meio de estratégias individuais e coletivas indissociáveis da malha de relações sociais em que se encontram os agentes econômicos de pequena escala. A eficácia de tais estratégias dependeria, precisamente, da liberdade relativa propiciada pela informalidade. Assim, os ativos materiais e sociais típicos da economia informal não deveriam ser menosprezados, mas valorizados pelos projetos de emancipação social.

Os grupos informais, segundo declaração deles próprios, correspondem a 30\% dos empreendimentos recenseados pelo segundo Mapeamento Nacional da Economia Solidária. Quando prosperam sem deixar a informalidade, é sinal de que seus integrantes abandonaram a atitude habitual de constante adaptação às circunstâncias e passaram a conceber sua atividade como uma força suscetível de criar novas situações e influenciar o ritmo das transformações que almejam. Essa mutação é favorecida quando se utilizam os recursos primários dos indivíduos e suas relações sociais, de forma a produzir uma metamorfose das relações de comensalidade, ancoradas nos laços pessoais e no costume, para uma lógica econômica propriamente empreendedora e solidária, sustentada em relações de cooperação (Razeto, 1990). Uma vez dotados desse novo substrato, os empreendimentos informais atenuam a instabilidade e a incerteza que afetam a vida material dos pobres, ao ampliarem as margens de retenção do valor excedente por eles produzido. Do ponto de vista da cultura econômica, eles contribuem para a racionalização da solidariedade, uma vez que estimulam o seu exercício intencional e cotidiano (Gaiger, 2006). Ao mesmo tempo, propiciam vivências de trabalho de conteúdo axiológico e projetivo, 
que estimulam a formação de sujeitos.

Sumariamente, pode-se afirmar que as práticas populares costumeiras de ajuda mútua, ao lado das experiências parcialmente institucionalizadas de associativismo e cooperativismo, constituem as vertentes historicamente mais arraigadas da economia solidária, ao passo que a economia popular funcionou como um novo vetor, decisivo para a taxa de crescimento recente dos empreendimentos solidários. A expansão da economia solidária nas últimas duas décadas, porém, não haveria ocorrido sem a conjunção de vários fatores, estruturais e conjunturais, cujo efeito resultante foi catalisar predisposições à associação e à solidariedade, latentes em diversas categorias de trabalhadores.

Essas predisposições existiram em várias modalidades associativas, urbanas, não urbanas e tradicionais. A próxima seção destaca a importância do segmento talvez menos estudado na economia solidária, mas que possui importância significativa em sua pluralidade cultural.

\section{O LUGAR DA TRADIÇÃO NA AN- CESTRALIDADE DA ECONOMIA SOLIDÁRIA}

Em países do Sul - entendido como metáfora do sofrimento e silenciamento provocado pelo colonialismo e suas consequências, ou como um Sul epistêmico e simbólico (Santos; Meneses, 2009) -, as práticas autóctones ou as referências culturais herdadas - mesmo que transformadas, recriadas, como no caso dos escravizados -, representaram um veio de produção de solidariedade na vida econômica de diferentes grupos sociais. Comunidades quilombolas, indígenas e ribeirinhas, por exemplo, integram atualmente redes de economia solidária, embora sempre tenham praticado o solidarismo econômico, a produção e o consumo sustentáveis em seus modos de vida, mesmo antes da formação dessas redes, às vezes por necessidade, como no caso dos quilombos, que precisavam ser produtivos e auto-organi- zados para sustentar um coletivo.

Tais grupos, bastante diversos na produção de suas identidades coletivas, se referem a situações sociais peculiares, com forte vínculo territorial. Como exemplificam Saraiva e Cruz no contexto do cerrado brasileiro: ${ }^{4}$

Essas comunidades possuem forte vínculo com a natureza e biodiversidade do Cerrado. A interação com o meio ambiente se deu num contexto de longa duração de convivência com plantas, morros, rios, animais, águas, paisagens e outros elementos. Assim, as experiências de vida (saberes e fazeres) dessas comunidades estão fortemente associadas ao Cerrado. Este bioma sempre foi utilizado por elas, seja para atender condições de subsistência (em momentos que o isolamento regional era uma condição real), ou na geração da renda familiar. [...]. Foi identificado que valores como o associativismo, a solidariedade, a coletividade, a cooperação, reconhecidos como valores sustentáveis, ainda estão presentes nas iniciativas de trabalho, produção e geração de renda de comunidades e grupos tradicionais da Chapada dos Veadeiros. (Saraiva; Cruz, 2014, p. 2)

Os conceitos de buen vivir ou sumak kawsay expressam, na América Latina, uma cosmovisão que Santos e Meneses (2009) chamam de epistemologias do Sul: saberes e práticas típicas de modos de vida tradicionais, também denominadas como culturas de resistência por Gauthier (1999). São culturas dotadas de sistemas de valores e uma gama de práticas que foram oprimidas, desvirtuadas, silenciadas ou mesmo aniquiladas pela colonização predatória e pela exploração capitalista. São diversas e podem conter diferentes conteúdos e índoles, mas, em muitos casos, já tinham germens do que iria se transformar em práticas econômicas solidárias, como o exemplo acima descreve. Foram esmagadas e, por isso, expressam a amplitude e profundidade do sofrimento imposto a significativas parcelas da humanidade. Para Toledo (2001, p. 453):

Existem mais de 300 milhões de pessoas pertencen-

${ }^{4}$ É a segunda maior formação vegetal brasileira, típica de locais com as estacõos climáticas bem definidas. Estendia-se, originalmente, por uma área de 2 milhões de $\mathrm{km}^{2}$, abrangendo dez estados do Brasil Central. Hoje, restam apenas $20 \%$ desse total. 
tes a povos e comunidades tradicionais vivendo em 75 dos 184 países do mundo, ocupando praticamente cada um dos principais biomas do planeta. Eles são também chamados de autóctones, minorias ou primeiras nações, dependendo dos critérios de definição. Eles apresentam todos ou parte dos seguintes critérios: (a) são descendentes dos primeiros habitantes de territórios que foram conquistados durante os Descobrimentos, (b) são povos dos ecossistemas, tais como agricultores, pastores, caçadores, extrativistas, pescadores e ou artesãos que adotam uma estratégia multiuso na apropriação da natureza, (c) praticam formas de produção rural de pequena escala e intensiva em trabalho, produzindo pequenos excedentes, apresentando necessidades satisfeitas com reduzida utilização de energia, [...] (f) apresentam uma visão de mundo especifica consistindo de uma atitude de proteção e não materialista em sua relação com a terra e os recursos naturais baseada num intercâmbio simbólico com o mundo natural.

A questão do desenvolvimento sustentável dos povos indígenas, por exemplo, é complexa e sensível em toda a América Latina, especialmente diante da hegemonia do agronegócio, que representa o avesso dos sistemas agrícolas tradicionais. Muitas vezes expulsos de suas terras e referências de vida, perderam sua autonomia econômica e sua referência ancestral, tendo de problematizar os processos de resistência (preservação de sua autonomia cultural), apropriação (capacidade de decisão sobre elementos culturais alheios) e inovação :ิ (criação de novos elementos culturais próث̈ prios) (Tuxá, 2011).

Em alguns casos, remanescentes de quilombos acabaram se integrando às cidades, constituindo os quilombos urbanos. No segundo mapeamento nacional da economia solidá$\therefore$ ria, foi identificado um percentual de $11 \%$ de $\therefore$ EES que se declararam pertencentes a algum के povo ou comunidade tradicional. Desses 11\%, $\therefore$ em um universo de 2.161 EES, encontramos o percentual de 19,9\% de empreendimentos de comunidades quilombolas, $12,7 \%$ de povos indígenas, $12,3 \%$ de ribeirinhos, $10,8 \%$ de "população negra" (não identificada com a figura do quilombo), 10,4\% de pescadores artesanais, $8,5 \%$ de extrativistas, $3 \%$ de cabo- clos, $1 \%$ de comunidades de terreiro e $21 \%$ de "outras comunidades tradicionais", além das descritas nas categorias listadas no questionário. Um estudo interessante, que apontamos como possibilidade futura, pois não o faremos no espaço deste texto, seria cruzar esses dados com informações relativas a ser o EES urbano, rural ou urbano e rural, bem como com outras variáveis significativas, ou seja, aprofundar os cruzamentos com base nos dados do segmento dos $11 \%$ de povos tradicionais.

Em Porto Alegre (RS), há um exemplo significativo da realidade dos quilombos urbanos na comunidade da Família Silva, há 70 anos instalada num bairro que, recentemente, se tornou muito valorizado em termos imobiliários e que mostra bem as tentativas de expulsão e aniquilamento dessas comunidades com características tradicionais, no seio das grandes cidades. Os quilombolas possuem uma identidade étnica, uma ancestralidade comum, que impacta em suas formas de organização política e social, e também em elementos linguísticos e religiosos. Por exemplo, o Quilombo Silva tem um grupo atuante, cujas lideranças praticam uma militância ativa em movimentos sociais urbanos, procurando articular-se com outras demandas da cidade. Na luta por reconhecimento, a Família Silva se organiza em diferentes frentes: grupos de mulheres, de jovens, de arte e de capoeira. Isso mostra como sua tradição incorpora elementos de inovação das cidades onde se inserem, passando a vivenciar situações culturais hibridas e, por vezes, contraditórias (Conceição, 2007; Freitag, 2007).

Poderíamos pensar também nas diversas etnias indígenas presentes no continente latino-americano; Segundo Clastres (1974), a etnia Yanomami tem um modo de vida em que a liderança tribal é exercida por mérito e capacidade de mediar conflitos, devendo haver consultas ao coletivo quando de decisões importantes. Nas epistemologias do Sul, há práticas que dialogam com - e são complementares aos - conceitos fundantes da democracia ocidental. Haveria necessidade de um procedimento de tradução 
para criar inteligibilidade entre diferentes sujeitos, grupos e comunidades de alguma forma praticantes desses conceitos (Santos, 2002).

Temos perspectivas bastante diversas quando ao modo de as sociedades lidarem com a presença das culturas de resistência, dependendo do contexto onde se encontram. Um exemplo interessante está no Equador, um país que discutiu e buscou incorporar o conceito de Sumak Kawsay ou Buen Vivir nas práticas institucionais (Brandão, 2013). Escrevendo sobre a comparação desse paradigma com o do desenvolvimento local, Andino (2014) considera que o paradigma do Bem Viver está ligado à prática quotidiana da ética em relação aos outros. Isso tanto para o mundo indígena, em que a participação aparece como uma prática contínua na tomada de decisões e na busca do bem comum, como para outros grupos, tais como montubios, camponeses e mestiços, que entendem a participação necessariamente estendida às situações cotidianas, como a rua, a escola, o bairro onde vivem.

No Brasil, igualmente, tem havido mobilizações das culturas de resistência, com participação de diversos grupos em movimentos sociais e nas redes de economia solidária, inspiradas também na ideia de produzir para viver, e não para acumular. Isso tudo se soma às descobertas do Mapeamento, aumentando a amplitude antropológica da compreensão do mundo plural que abarca o fenômeno da economia solidária.

Em agosto de 2004, em Luziânia (DF), ocorreu o Primeiro Encontro Nacional de Comunidades Tradicionais, do qual participaram, além de povos indígenas e quilombolas, agroextrativistas, seringueiros, quebradeiras de coco babaçu, pescadores artesanais e caiçaras, geraizeiros (habitantes do sertão), vazanteiros (pequenos agricultores cujo plantio e colheita estão associados aos ciclos de enchente, cheia e vazante dos rios), pantaneiros, ciganos, pomeranos, comunidades de terreiro, fundos de pasto, faxinais (camponeses que se caracterizam principalmente pelo uso coletivo da terra e dos recursos florestais e hídricos) e ribeirinhos do São Francisco (IPEA, 2012). Para esses sujeitos, a luta política para manutenção de seus modos de vida não acontece descolada do trabalho e da sustentação econômica das famílias, elemento também presente em empreendimentos urbanos da economia solidária, como no caso do exemplo do quilombo Silva mencionado anteriormente. O grupo reunido produziu um documento publicado no site do FBES, que expressa seu modo de ver o mundo:

Nós, povos indígenas, quilombolas, pescadores artesanais, seringueiros, vazanteiros, quebradeiras de coco, litorâneos e ribeirinhos, comunidades de fundo e fecho de pasto e posseiros de todo o Brasil, mulheres e homens de luta, nos encontramos em Luziânia GO, nos dias de 25 a 28 de fevereiro, para partilhar cruzes e esperanças e repensar as nossas lutas frente ao avanço cada vez mais acelerado e violento do capital e do Estado sobre os nossos direitos. Vivemos o encontro como um momento histórico, que confirma a realidade indiscutível de uma articulação e aliança entre povos indígenas, quilombolas, pescadores artesanais e camponeses. O diálogo entre povos e comunidades que expressam culturas e tradições diferentes, frequentemente marcadas por preconceitos e rejeição, volta-se para a defesa e reconquista dos nossos territórios. Este é o processo que unifica sonhos e estratégias na construção de um País diferente que se opõe à doença capitalista do agro e hidronegócio, mineração, hidroelétricas, incentivada e financiada pelo Estado, em nome do chamado desenvolvimento e crescimento do Brasil. Não nos deixaremos curvar pelo avanço insaciável do capitalismo com o seu cortejo de políticas governamentais nefastas e genocidas. Território não se negocia não se vende não se troca. É o espaço sagrado onde fazemos crescer a vida, nossa cultura e jeito de viver, nos organizar, ser livres e felizes. “Territórios livres, já!!!”. (FBES, 2013)

Importante é mencionar que, três anos depois, foi instituída a Política Nacional de Desenvolvimento Sustentável dos Povos e Comunidades Tradicionais, através do decreto $n^{\circ}$ 6.040, datado de 07/02/2007. No Artigo $3^{\circ}$, tem-se que os Povos e Comunidades Tradicionais são grupos culturalmente diferenciados que possuem formas próprias de organização social, que ocupam e usam territórios e recur- 
sos naturais como condição para sua reprodução cultural, social, religiosa, ancestral e econômica, utilizando conhecimentos, inovações e práticas gerados e transmitidos pela tradição.

No âmbito do Mapeamento citado, concluído em 2013, o conceito de povos ou comunidades tradicionais também se refere a esses grupos culturalmente diferenciados e que se reconhecem como tal, ocupando territórios e recursos naturais para reproduzir suas condições de vida, confundindo-se, eventualmente, com a concepção de etnia. Valem-se de conhecimentos e práticas transmitidos pela tradição de seus antepassados, e os dados apontam, em perspectiva regional, uma maioria (relativa ao número total de EES mapeados, considerando cada região do país) de empreendimentos de comunidades tradicionais na região norte (23\% do total), e uma minoria na região sudeste (5,7\% do total) (Gaiger, 2014).

As políticas públicas no campo de trabalho e renda, especialmente no âmbito da SENAES, têm buscado, pelo menos em suas pretensões, a inclusão e a valorização das iniciativas econômicas dessas populações que, segundo Tiriba e Fischer (2015, p. 409), constituem mediações de primeira ordem. Elas, ao contrário das mediações de segunda ordem do capital, têm como finalidade a preservação das funções vitais de reprodução individual e da totalidade dernos, seja nos modos de trabalhar, dividir os excedentes ou viver em comunidade.

Portanto, essa realidade multiforme, presente em toda a América Latina, mostra como as denominações dos formatos organizativos presentes no campo da economia solidária podem ser imprecisas diante de realidades tão díspares - e tão distintas do conceito europeu de empresa social. Essa é uma razão para que se destaque a importância de pesquisa com esses grupos, buscando caracterizar tipologias regionais, captando e analisando - ao menos parcialmente - a enorme diversidade e a riqueza cultural da economia solidária no mundo. O Mapeamento nos parece um bom ponto de partida para estudos que aprofundem essa diversidade, qualitativamente.

\section{A GUISA DE CONCLUSÃO: é preci- so reconhecer a diversidade}

Já acumulamos uma base de dados considerável a respeito do fenômeno dos EES nas duas últimas décadas, para que possamos afirmar, hoje, sua pluralidade e a importância do reconhecimento da diversidade de experiências que os compõem, ampliando o leque de alternativas de existência social e práticas econômicas. De acordo com uma pesquisa nacional a respeito da gênese de empreendimentos solidários bem-sucedidos (Gaiger, 2004), uma circunstância significativa é o fato de estarem vinculados a setores populares, tanto urbanos como não urbanos, dotados de referências culturais e de lideranças genuínas que valorizam a vida comunitária, os modos de vida tradicionais, o associativismo ou as mobilizações de classe, a depender do contexto. Isso se verifica, sobretudo, quando tais referências se alimentam em vivências próprias de organização e luta, nas quais esses protagonistas forjaram identidades comuns, laços de confiança e competências para a defesa coletiva de interesses e aspirações. Exemplos a serem mencionados são as experiências de Bolívia e Equador que, ao reconhecerem a natureza (Pacha Mama ou Madre Tierra) como central em suas Constituições (Equador em 2008 e Bolívia em 2009), incorporando as cosmovisões indígenas nos 
textos constitucionais, reconhecem o valor e a primazia da economia solidária, não somente como prática econômica, mas como parte fundamental da riqueza cultural de seus países.

Salvo raras exceções, os empreendimentos solidários não substituem integralmente nem prescrevem as formas populares de economia existentes, e tal não aconteceu nos referidos países. Seu efeito principal consiste em reorganizar os fatores produtivos, materiais e humanos da economia popular praticada por múltiplos agentes, por meio de mutações progressivas que a afastam de suas formas mais degradadas e atenuam seu caráter subalterno no interior da economia capitalista, gerando maior pluralidade econômica e diversidade social.

No Brasil, um quadro mais positivo para o reconhecimento público da diversidade de atores que constituem essas práticas começou a instaurar-se, a partir da transição democrática, na segunda metade dos anos 1980, quando a realidade política do país encontrou condições mais favoráveis à participação cidadã e ao reconhecimento das demandas sociais variadas pela esfera pública e pelo aparato estatal. Com as amplas manifestações sociais que culminaram na promulgação da "Constituição cidadã”, em 1988, sucessivas mobilizações coletivas trouxeram ao cenário político atores até então relegados a um papel marginal ou de ausência produzida (Sader, 1988; Santos, 2002). A redemocratização do país torna mais propício o ambiente no qual se dará a emergência da economia solidaria como movimento, alguns anos depois, embora, à época da Constituição, a pauta não incluísse o tema. De qualquer modo, aquele momento fez emergir os grupos e entidades empenhados em levar à frente experiências locais de organização e de defesa de interesses comuns. Com o propósito de vencer sua dispersão inicial, programas de apoio mais abrangentes estimularam a multiplicação de agências e instituições de fomento, ensejando a convergência entre visões e métodos de atuação. Assim sendo, a economia solidária passou a designar, sucessivamente, um conjunto de práticas econômicas referenciadas em princípios de cooperação e autogestão, um movimento social comprometido com a transformação social e, por fim, um setor constitutivo da ação pública.

Ao postular esse reconhecimento legal, os atores sociais da economia solidária têm a seu favor um relativo consenso nacional sobre as características fundamentais das organizações econômicas solidárias em questão (que não incluem as organizações não aderentes aos princípios basilares da economia solidária, como as grandes cooperativas ligadas à OCB, por exemplo).

Contudo, ainda há uma lacuna, de especial importância, que se refere ao reconhecimento da diversidade de práticas, racionalidades, etnias, gêneros, territórios, modos e expressões de vida. Para que haja efetivo acolhimento por parte das políticas públicas e das comunidades de entorno aos empreendimentos, é preciso reconhecer, divulgar e identificar as necessidades desses múltiplos estilos e condições de vida presentes na economia solidária. Os órgãos representativos dos trabalhadores associados, os pesquisadores que produzem conhecimento acadêmico, os formuladores e executores das políticas são agentes importantes nesse processo de reconhecimento, ampliando também o escopo das ciências sociais em relação ao trabalho, numa superação de certa ênfase que é dada, ainda, a uma classe trabalhadora urbana.

Questões a serem aprofundadas permanecem como uma proposta para pesquisas futuras a serem produzidas: Como os empreendimentos ou comunidades tradicionais absorvem e processam inovações de variados tipos? Quais os impactos nos seus modos de vida? Como os grupos sociais se apropriam e dão sentido às inovações e desafios, construindo realidades socioeconômicas variadas?

Segundo Moscovici (2004), há uma grande capacidade humana de criar realidades a partir dos processos de simbolização. Como a inteligibilidade plena do outro é da ordem do im- 
possível, há que revelar e analisar as diferenças e a pluralidade características da economia solidária, pois ainda há muito a descobrir. Os grupos de comunidades tradicionais demonstram a flexibilidade do panorama simbólico humano e suas distintas atribuições de sentido ao âmbito do econômico, do social e do político, que, conforme Jean Louis Laville, formam o tripé dos empreendimentos econômicos solidários.

Há que superar dualismos, como urbano versus rural, proletariado versus capital e compreender que, numa economia plural, formas distintas de produção e consumo podem ter seu espaço, desde que sejam oferecidas as condições - inclusive logísticas -, de atuação dos trabalhadores de distintas origens. Para tanto, impossível é ignorar a discussão em torno do marco legal da economia solidária, já que o existente ainda não contempla a diversidade de formas. Embora não seja intenção deste trabalho discutir essa questão específica, ficando esse aprofundamento para futuros trabalhos, aponta-se que, há pelo menos uma década, a criação de um marco legal adequado para a economia solidária tem sido um dos pontos centrais da agenda de empreendimentos, organizações de apoio e autoridades públicas. Registaram-se progressos em alguns setores, tais como cooperativas de trabalho, mas os obstáculos e as dificuldades persistem, no adiamento ڤิ da adoção de uma lei nacional específica. Além . de disputas entre atores sociais envolvidos na economia solidária, há uma grande oposição do setor cooperativo tradicional, cuja institucionalização ocorreu durante o regime militar, garantindo a unicidade de representação e vantagens के econômicas para as suas próprias organizações. $\therefore$ Essa lei precisaria abarcar distintos modelos de §ิ produção e comercialização em diversos terri-

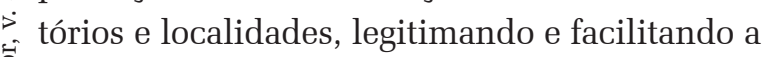
expressão da diversidade de formatos.

É um assunto que dá margem a controvérsias, por razões políticas, econômicas e ideológicas, mas o estabelecimento de um marco legal proprio para a economia solidária, em curto prazo, removeria obstáculos à inovação insti- tucional no Brasil, particularmente em relação à formação de agenda pública mais inclusiva, abrangente, participativa e aberta à diversidade. Em termos de potencialidades, em meio às tensões e disputas que os atores enfrentam, tanto em relação às formas econômicas tipicamente capitalistas, como às lógicas organizacionais opostas que se impõem por questões de poder (França Filho; Dzimira, 2014), podemos dizer que a economia solidária tem uma história bastante plural atrás de si e enseja potências variadas para o futuro, o qual, por sua vez, não tem direção certa nem sentidos pré-definidos, estando por ser construído e sem nenhuma garantia automática de sucesso para as lutas de seus múltiplos agentes. Como dizia o filósofo utópico Ernst Bloch (2005), junto a cada esperança há sempre um caixão à espera; as conquistas estão sempre por se manterem ou se desintegrarem, não cabendo uma interpretação necessitária da história. Alguns projetos possuem a característica da provisoriedade e da precariedade; outros se consolidam e logram êxitos e possibilidades de expansão. Contudo, cabe reforçar que as experiências e as redes que as expandem e articulam situam-se no âmbito do vasto campo para a regulação social, a ser levada a cabo pelos atores, no espaço entre o livre mercado desregulado e um eventual planejamento estatal (Vinha, 2003).

As formas de articulação dos interesses variados que os distintos sujeitos engendram podem propiciar o ativamento de recursos intangíveis que os fortalecem política e economicamente, a iniciar pelas outras formas de redistribuição dos excedentes econômicos e aprendizagens constantes que o trabalho autogestionado proporciona. O cenário nem sempre estável dos recursos oriundos de políticas públicas é um fator de risco, bem como a inexistência de uma posição de consenso entre os próprios integrantes da economia solidária, mas a história recente tem provado que os empreendimentos resistem, e os sujeitos continuam tecendo a teia heterogênea de elementos que tornam a outra economia cada vez mais 
variada e plural, a despeito das enormes dificuldades presentes.

Recebido para publicação em 08 de abril de 2016 Aceito em 25 de novembro de 2016

\section{REFERÊNCIAS}

ANDINO, V. Continuidades y rupturas entre los enfoques de economía solidaria y desarrollo local. In: JUBETO, Y; GURIDI L.; FERNÁNDEZ-VILLA, M. (Orgs.). Diálogos sobre Economía Social y Solidaria em Ecuador: encuentros $y$ desencuentros com las propuestas para otra economia. [S.1]: UPV/EHU, 2014. p. 59-148.

ANJOS, E. G. dos. Práticas e sentidos da economia solidária: um estudo a partir das cooperativas de trabalho. 2012 212f. Tese (Doutorado em Ciências Sociais) - Programa de Pós-graduação em Ciências Sociais, Unisinos, São Leopoldo, 2012.

BLOCH, E. O princípio esperança. Rio de Janeiro: UERJ/ Contraponto, 2005. v. 1.

BRANDÃO, P. $O$ novo constitucionalismo pluralisto Latino-Americano: participação popular cosmovisões indígenas (Sumak Kawsay e Pachamama). 2013. $156 f$. Tese (Doutorado)- Programa de Pós-Graduacão em Direito, Universidade Federal de Pernambuco, Recife, 2013.

BRASIL. Lei $n^{o}$ 10. 406, de 10 de janeiro de 2002. Institui o Código Civil. Disponível em: <http://www.planalto.gov.br/ ccivil_03/leis/2002/L10406compilada.htm> . Acesso em: 6 mai. $\overline{2} 013$.

CATTANI, A. et al. (Orgs.). Dicionário internacional da outra economia. Coimbra: Almedina, 2009.

CLASTRES, P. A sociedade contra o Estado: pesquisas de antropologia política. São Paulo: Coisak \& Naify, 1974. 288 p.

CONCEIÇÃO, L. Solidarismo em comunidades remanescentes de quilombos do RS. 2007, 111f. Monografia (Conclusão do Curso) - Universidade do Vale do Rio dos Sinos, São Leopoldo, 2007.

CORAGGIO, J. Política social y economia del trabajo. Madrid: Miño y Dávila Editores, 1999. 225 p.

DEPARTAMENTO INTERSINDICAL DE ESTATÍSTICA E ESTUDOS SOCIOECONÔMICOS (DIEESE). O quadro geral da informalidade na economia solidária. In: Informalidade na economia solidária. São Paulo: DIEESE mar. 2016. (Cadernos de debates do observatório nacional da economia solidária e do cooperativismo, 1).

DUBEUX, A. et al. Estudio de casos brasileños:la dinámica de relaciones entre los foros de economía solidaria y las políticas públicas para laeconomía solidaria en Brasil. Foro Internacional sobre la Economía Social y Solidaria - FIESS Montréal: Chantier de l'ÉconomieSociale, 2011. 42 p.

FORÚM Brasileiro deEconomia Solidária(FBES).Disponível em: <http://www.fbes.org.br/index.php?option = com content\&task $=$ view\&id $=7356 \&$ Itemid $=62>$. Acesso em 13 maio 2013.

FRANÇA FILHO, G. C.; DZIMIRA, S. Economia solidária e dádiva. $O \& S$, Salvador, v. 6, n. 14, p. 141-183, 2014.

FREITAG, B. Teorias da cidade. Campinas: Papirus, 2007. 190 p.

GAIGER, L. I (Org). Sentidos e experiências da economia solidária no Brasil. Porto Alegre: UFRGS, 2004. de dados nacionais. São Leopoldo: Oikos, 2014.

A racionalidade dos formatos produtivos autogestionários. Soc. e estado, Brasília-DF, v. 21, n. 2, p. 513-544, 2006.

Relações entre equidade e viabilidade nos empreendimentos solidários. Lua Nova, São Paulo, n. 83, p. 79-109, 2011.

GAUTHIER, J. O que é pesquisar: entre Deleuze-Guattari e o candomblé, pensando mito, ciência, arte e culturas de resistência. Educ. Soc., São Paulo, v. 20, n. 69, p. 13-33, 1999

INSTITUTO DE PESQUISA ECONÔMICA APLICADA (IPEA). A Comissão Nacional de desenvolvimento sustentável dos povos e comunidades tradicionais na visão de seus membros. Relatório de pesquisa. 2012. Disponível em: <http://www.ipea.gov.br/agencia/images/stories/PDFs/ relatoriopesquisa/120409 relatorio comunidades tradicionais. pdf $>$. Acesso em: 10 ago. 2014

MOSCOVICI, S. Representações sociais: investigações em psicologia social. 2. ed. Petrópolis: Vozes, 2004.

NAMORADO, R. A economia social: uma constelação de esperanças. Coimbra: CES-FEUC, 2004. Disponível em: $<$ http://www.ces.uc.pt/publicacoes/oficina/ficheiros/213. pdf>. Acesso em: 20 out. 2015.

NUNES, C. Cooperativas, uma possível transformação identitária para os trabalhadores do setor informal. Soc. e estado, Brasília-DF, v. 16, n. 1-2, p. 134-158, 2001

PINTO, J. Economia solidária: de volta à arte da associação. Porto Alegre: UFRGS, 2006.

RAZETO, L. Las empresas alternativas. Montevidéu: Editorial Nordan-Comunidad, 1990. 200 p.

SADER, E. Quando novos personagens entram em cena: experiências, falas e lutas dos trabalhadores da Grande São Paulo (1970-80). São Paulo: Paz e Terra, 1988. 341 p.

SANTOS, B. S. S. Para uma sociologia das ausências e uma sociologia das emergências. Revista Crítica de Ciências Sociais, Coimbra, n. 63, p. 237-280, 2002.

SANTOS, B. S.; MENESES, M. P. Epistemologias do Sul. Coimbra: Almedina, 2009. $532 \mathrm{p}$.

SARAIVA, R. C. F.; CRUZ, T. C. da S. A cultura, os saberes e a tradição no arranjo da economia solidária ambiental. Cadernos de Agroecologia, Mato Grosso do Sul, v. 9, n. 3, p. 1-2, 2014

SCHNEIDER, J.; LAUSCHNER, R. Evolução e situação atual do cooperativismo brasileiro. In: . O cooperativismo no Brasil: enfoques, análises e contribuição. Rio Grande do Sul: Friedrich Neumann e Associação de Orientação às Cooperativas, 1979. p. 1-58.

SINGER, P.; SOUZA, A. (Orgs.). A economia solidária no Brasil: a autogestão como resposta ao desemprego. São Paulo: Contexto, 2002. 360 p.

TIRIBA, L.; FISCHER, M. C. B. Espaços/tempos milenares dos povos e comunidades tradicionais: notas de pesquisa sobre economia, cultura e produção de saberes. $R$. Educ. Públ. Cuiabá, v. 24, n. 56, p. 405-428, maio/ago. 2015.

TOLEDO, V. M. Povos/comunidades tradicionais e a biodiversidade. In: LEVIN, S. et al., (Orgs.). Encyclopedia of Biodiversity. [S.1.]: Academic Press, 2001.p. 451-463.

TUXÁ, R. C. de A. Educação escolar indígena como novo paradigma na visão indígena: experiências, conquistas e desafios. Tellus, Mato Grosso, n. 20, p. 275-288, jan./jun. 2011.

VINHA, V. da. Polanyi e a nova sociologia econômica. Econômica, Rio de Janeiro, v. 3, n. 2, p. 207-230, 2003.

GAIGER, L. I. A Economia Solidária no Brasil: uma análise 


\section{ABOUT THE DIVERSITY OF FORMATS AND SOCIAL ACTORS IN THE FIELD OF SOLIDARITY ECONOMY}

\author{
Marilia Verissimo Veronese \\ Luiz Gaiger \\ Adriane Vieira Ferrarini
}

This article presents a comprehension of solidarity economic projects from the multiform reality of solidarity economy in Brazil. This article is a varied set of initiatives still seeking institutional identity and a proper legal framework, since they do not fit into traditional cooperativism or the so-called third sector. Using a set of studies conducted both in terms of conceptualization and of typological formulation such as ethnographic design, this study discusses the plural configuration of solidarity projects, analyzing different social actors in focus, such as urban, rural and traditional environments. It tries to demonstrate the cultural and symbolic diversity that exist, as well as its multiple origins and current challenges, as an example of the search for a specific legal milestone for the field.

Keywords: Sociology. Solidarity projects. Cultural Diversity. Associativism. Tradicional Practices and Autochthonous.

\section{A PROPOS DE LA DIVERSITE DES FORMATS ET DES ACTEURS SOCIAUX DANS LE DOMPAINE DE L'ECONOMIE SOLIDAIRE}

\author{
Marilia Verissimo Veronese \\ Luiz Gaiger \\ Adriane Vieira Ferrarini
}

Larticle présente une compréhension des entreprises économiques solidaires à partir de la réalité multiforme de l'économie solidaire au Brésil. Il s'agit d'un ensemble varié d'initiatives qui est encore à la recherche d'une identité institutionnelle et d'une ébauche juridique adaptée qui n'entre pas dans la conception de coopérativisme traditionnel ni dans le dit troisième secteur. En se basant sur un ensemble d'études déjà réalisées, autant en termes de conceptualisation et de formulation typologique que de dessin etnographique, le texte montre la configuration plurielle des entreprises solidaires en analysant les divers acteurs sociaux mis en évidence, urbains, ruraux et traditionnels et essaie de démontrer la diversité culturelle et symbolique existante ainsi que leurs origines multiples et leurs défis actuels, tel que par exemple la recherche d'un label légal spécifique pour le monde rural.

Mots-CLÉs: Sociologie. Entreprise solidaire. Diversité Culturelle. Associations. Pratiques Traditionnelles et Autochtones.

\footnotetext{
Marilia Verissimo Veronese - Doutora em Psicologia Social pela PUCRS. Professora do Programa de Pós Graduação em Ciências Sociais da Universidade do Vale do Rio dos Sinos (UNISINOS). Integra o Grupo de Pesquisa em Economia Solidária e Cooperativa - EcoSol, desenvolvendo pesquisas na área de economia solidária, autogestão e alternativas econômicas. Publicações recentes: Risco invisível: trabalho e subjetividade no setor elétrico. Psicologia \& Sociedade, 29: e131134; Associativismo entre catadores de material reciclável urbano. Contemporânea - Revista de Sociologia da UFSCar , v. 6, p. 213-236, 2016; Théorie de l'entreprise sociale et pluralisme: L'entreprise sociale de type solidaire. Revue Interventions économiques , v. 54, p. 1-14-14, 2016.

Luiz Gaiger - Doutor em Sociologia pela Université Catholique de Louvain (Bélgica). Professor do Programa de Pós-graduação em Ciências Sociais da UNISINOS. Integra o Grupo de Pesquisa em Economia Solidária e Cooperativa - EcoSol, desenvolvendo pesquisas na área de economia solidária, empresas sociais e alternativas econômicas. Suas mais recentes publicações, são: Gaiger, Luiz. A descoberta dos vínculos sociais. São Leopoldo: Editora Unisinos, 2016; Gaiger, Luiz; Santos, Aline (Orgs.). Solidariedade e ação coletiva. Trajetórias e experiências. São Leopoldo: Editora Unisinos, 2017.

Adriane Vieira Ferrarini - Doutora em Sociologia pela Universidade Federal do Rio Grande do Sul (UFRGS). Professora do Programa de Pós-graduação em Ciências Sociais UNISINOS, Coordenadora do Núcleo de Pesquisa em Economia Solidária e Cooperativa, desenvolvendo pesquisas na área de economia solidária, inovação social, combate à pobreza, política pública. Publicações recentes: $O$ ethos da inovação social: implicações ético-políticas para o estudo de práticas produzidas em diferentes ambientes. Contemporânea - Revista de Sociologia da UFSCar, v. 6, p. 447-466, 2016; Théorie de l'entreprise sociale et pluralisme: L?entreprise sociale de type solidaire. Revue Interventions Économiques, v. 54, p. 1-14, 2016; A educação popular na formação de trabalhadores da economia solidária no Rio Grande do Sul: avanços políticos e desafios pedagógicos. Revista Ciências Sociais Unisinos, v. 51, p. 212/-221, 2015.
} 